\title{
Evaluation of Thellungiella halophila ST7 for improving salt tolerance in cotton
}

\author{
ALI Mohsin' ${ }^{1}$, NAZISH Tahmina', JAVAID Ayesha' ', ZHU Yonghong ${ }^{2}$, LI Jing ${ }^{2}$, ZHANG Huangyang ${ }^{2}$, WU Jie', \\ XIANG Chengbin ${ }^{1}$, WU Shenjie ${ }^{3 *}$ and ALFATIH Alamin ${ }^{1 *}$
}

\begin{abstract}
Background: Gossypium hirsutum (upland cotton) is one of the principal fiber crops in the world. Cotton yield is highly affected by abiotic stresses, among which salt stress is considered as a major problem around the globe. Transgenic approach is efficient to improve cotton salt tolerance but depending on the availability of salt tolerance genes.

Results: In this study we evaluated salt tolerance candidate gene ST7 from Thellungiella halophila, encoding a homolog of Arabidopsis aluminum-induced protein, in cotton. Our results showed that ThST7 overexpression in cotton improved germination under $\mathrm{NaCl}$ stress as well as seedling growth. Our field trials also showed that ThST7 transgenic cotton lines produced higher yield under salt stress conditions. The improved salt tolerance of the transgenic cotton lines was partially contributed by enhanced antioxidation as shown by diaminobenzidine (DAB) and nitrotetrazolium blue chloride (NBT) staining. Moreover, transcriptomic analysis of ThST7 overexpression lines showed a significant upregulation of the genes involved in ion homeostasis and antioxidation, consistent with the salt tolerance phenotype of the transgenic cotton.
\end{abstract}

Conclusions: Our results demonstrate that ThST7 has the ability to improve salt tolerance in cotton. The ThST7 transgenic cotton may be used in cotton breeding for salt tolerance cultivars.

Keywords: Gossypium hirsutum, Aluminum-induced protein, Salinity, Thellungiella halophila, ST7, Salt tolerance

\section{Background}

Salinity stress is one of the most acute and critical abiotic stress that limits the growth and yield of crops (Tester and Davenport 2003; Parida et al. 2004). There is an immediate requirement to develop new varieties of salt tolerant crops that can cope with high salinity environments (Ma et al. 2020). To withstand the salt stress, plants have developed intricate mechanisms (Blumwald

\footnotetext{
*Correspondence: sj_wu@126.com; alfatih@ustc.edu.cn; 2725873001@qq.com

${ }^{1}$ Division of Molecular \& Cell Biophysics, School of Life Sciences, Hefei National Science Center for Physical Sciences at the Microscale, University of Science and Technology of China, The Innovative Academy of Seed Design, Chinese Academy of Sciences, Hefei, Anhui, China

${ }^{3}$ College of Life Sciences, Shanxi Agricultural University, Taiyuan 030031, China

Full list of author information is available at the end of the article
}

2000). The higher concentration of sodium chloride in the environment disturbs the overall cellular homeostasis in plants (Zhu 2002). Plants have developed strategies to avoid the injuries from high $\mathrm{NaCl}$ levels (Flowers and Colmer 2008), for instance, sequestration of $\mathrm{NaCl}$ into large vacuole (Martinoia et al. 2007). Alteration of the ion transport mechanisms may also help plants in response against salt stress (Darko et al. 2020). The mechanisms of salt tolerance also include the acclimatization to the osmotic stress, cytoplasmic $\mathrm{Na}^{+}$exclusion, $\mathrm{Na}^{+}$and $\mathrm{Cl}^{-}$accumulation tolerance and compartmentalization, occurring in a disciplined manner (Munns and Tester 2008).

Cotton is considered as one of the principal fibers and oil seed crop. It is also used in medicinal products, household stuff, and as major raw material in textile industry. It fulfils 35\% of world's fiber need (Martinez et al. 2018). 
Abiotic stresses cause about 50\% reduction of the global cotton yield. Salinity stress is among the most important restriction for cotton crop productivity and growth (Wang et al. 2003).

A number of studies have been done in order to develop salt tolerant cotton varieties via transgenic approach. For instance, $T s V P$, a $\mathrm{H}^{+}$-PPase gene from Thellungiella halophilla, was demonstrated to improve the growth of root and shoot and photosynthetic activity under high salinity in cotton (Lv et al. 2008). The transgenic plants showed decreased membrane ion leakage and malondialdehyde level as compared with the wild type because the transgene assisted the sequestration of $\mathrm{Na}^{+}$and $\mathrm{Cl}^{-}$ in the vacuoles ( $\mathrm{Lv}$ et al. 2008). The expression of $T s V P$ also enhanced the emergence and survival rate of cotton, improved fiber quality under high saline environment (Zhang et al. 2016a, b). Another study demonstrated that the expression of AVP1 encoding vacuolar pyrophosphatase from Arabidopsis thaliana improved growth of the transgenic cotton and the fiber yield under salt stress (Pasapula et al. 2011). Cheng et al. (2018) showed the coexpression of AtNHX1 gene from Arabidopsis thaliana and TsVP gene from Thellungiella halophilla in cotton enhanced emergence rate and yield of the transgenic cotton under high saline environment (Cheng et al. 2018).

Using a functional gene mining method, $\mathrm{Du}$ et al. (2008) identified SALT TOLERANCE (ST) genes from salt cress (ThST7). ThST7, one of the identified genes, encodes an auxin/aluminum-responsive protein $(\mathrm{Du}$ et al. 2008). The Arabidopsis homologue of ThST7gene is At5G19140 with 94\% similarity to the ThST7 amino acid sequence ( $\mathrm{Du}$ et al. 2008). A study conducted by Lin et al. showed that the transcript level of At5G19140 gene increased in hypoxia stress (Lin et al. 2017). This aluminum-induced protein was also found responsive to PEG stress in wheat (Pál et al. 2018). Putrescine treatment was found to upregulate the aluminum induced protein genes (Agarwal et al. 2009).

In this study, we aimed to evaluate the salt tolerance conferred by ThST7 gene we previously isolated from Thellungiella halophilla in cotton. Our results not only showed improved germination and growth performance of transgenic cotton lines under salt stress in controlled environment but also showed better performance in field trials.

\section{Results}

ThST7 enhanced cotton seed germination under salt stress

To evaluate ThST7-conferred salt tolerance in cotton, we made the overexpression construct and obtained transgenic lines by Agrobacterium-mediated transformation (Additional file 1: Fig. S1A). The expression of the transgene ThST7 was verified in the transgenic cotton lines by reverse transcription polymerase chain reaction(RT-PCR) analysis (Additional file 1: Fig. S1B). $\mathrm{T}_{3}$ transgenic cotton seeds were assessed for germination either with $250 \mathrm{mmol} \cdot \mathrm{L}^{-1}$ or without $\mathrm{NaCl}$ stress. Both the control (CK) and transgenic (ST7-OE1 and ST7-OE2) cotton seeds were germinated at almost equal rate in absence of salt stress. Similarly, both CK and transgenic seeds attained stable germination rate at day 5-8 with initiation at the same time. While at $250 \mathrm{mmol} \cdot \mathrm{L}^{-1} \mathrm{NaCl}$ stress, germination rate of ST7-OE1 and ST7-OE2 transgenic cotton seeds was significantly higher $(\sim 37 \%$ and $33 \%$, respectively) than CK seeds $(\sim 20 \%)$ on the 8 th day of seed sowing. Transgenic seeds germinated 1 day earlier than the CK (Fig. 1A, B).

Under normal growth condition, both CK and the transgenic lines revealed no obvious difference after growing for 2 weeks in soil, while in soil containing $250 \mathrm{mmol} \cdot \mathrm{L}^{-1} \mathrm{NaCl}$, survival rate of ST7-OE1 ( 32\%) and ST7-OE2 $(\sim 38 \%)$ seedlings was significantly higher than that of the CK seedlings ( 20\%) (Fig. 1C, D). These results indicated that ThST7 overexpression in cotton improved seed germination under salt stress.

\section{ThST7 enhanced seedling growth under salt stress}

To demonstrate the ThST7-conferred salt tolerance in seedlings, we conducted seedling growth and survival in hydroponic culture with 0 or $140 \mathrm{mmol} \cdot \mathrm{L}^{-1} \mathrm{NaCl}$ as described in "Methods" section. After $140 \mathrm{mmol} \cdot \mathrm{L}^{-1}$ $\mathrm{NaCl}$ treatment for 3 days, the survival rate of transgenic seedlings $(\sim 70 \% \sim 78 \%)$ was significantly higher than that of $\mathrm{CK}(\sim 20 \%)$, while in absence of $\mathrm{NaCl}$ stress, transgenic and CK seedlings survived almost equally (100\%) (Fig. 2A, B). We also examined the salt tolerance of transgenic seedlings grown in soil. The 20-days-old seedlings were treated without or with $300 \mathrm{mmol} \cdot \mathrm{L}^{-1} \mathrm{NaCl}$ for 10 days (Fig. 2C). Under no salt control condition, no apparent difference was observed between the CK and the transgenic lines, while under salt stress condition the CK was more sensitive to the salt stress compared with the transgenic plants. The transgenic limes exhibited significantly higher survival rates $(\sim 76 \% \sim 78 \%)$ than the CK ( 40\%) (Fig. 2C, D).

\section{ThST7 enhanced the tolerance against oxidative stress}

To detect the level of reactive oxygen species (ROS) under salt treatment in transgenic lines, we performed diaminobenzidine (DAB) and nitrotetrazolium blue chloride (NBT) staining of cotton leaf. DAB staining visualized the accumulation of $\mathrm{H}_{2} \mathrm{O}_{2}$ while the NBT staining depicted the presence of superoxide radicals. Under the normal condition, the DAB and NBT staining were similar between the $C K$ and transgenic lines. However, under the salt treatment $(0.6 \% \mathrm{NaCl})$, less $\mathrm{DAB}$ staining 

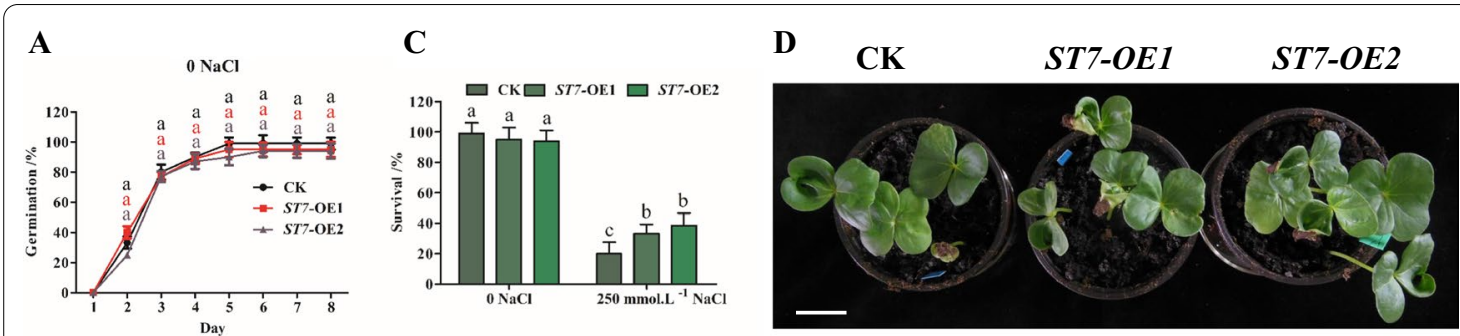

$\mathbf{0} \mathrm{NaCl}$
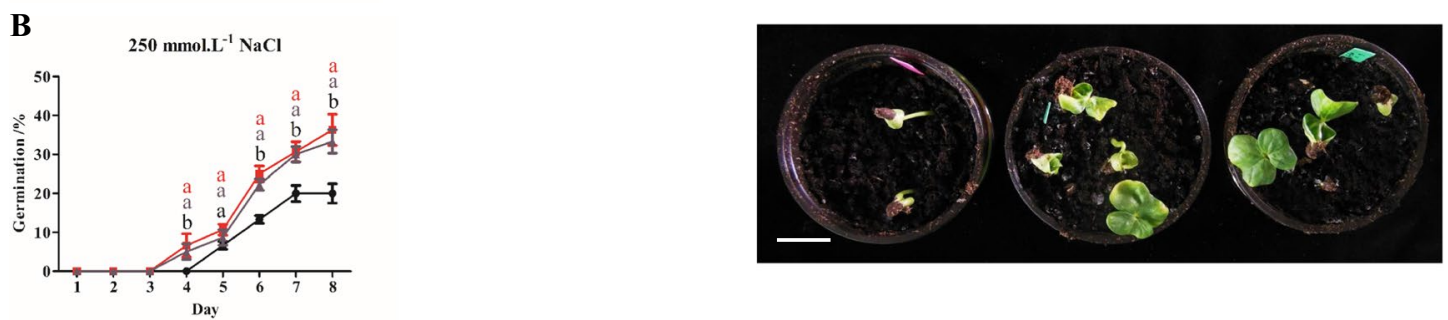

$250 \mathrm{mmol} \cdot \mathrm{L}^{-1}$

$\mathrm{NaCl}$

Fig. 1 Expression of ThST7 gene in cotton confers salt tolerance phenotype in seed germination. A Seed germination curve. Seeds of the wild type (CK) and ST7-OE lines were germinated in soil watered with 0 or $250 \mathrm{mmol} \cdot \mathrm{L}^{-1} \mathrm{NaCl}$ for 8 days and germination percentage was recorded every day. Values are mean \pm SD (10 seeds per replicate, five replicates per treatment). Different letters denote significant differences $(P<0.05)$ from Duncan's multiple range tests. B Seedling survival ratio. The above germinated seeds were grown for 2 weeks before seedling survival ratio was recorded. Values are mean \pm SD (10 plants per replicate, five replicates per treatment). Different letters denote significant differences $(P<0.05)$ from Duncan's multiple range tests. C Growth of germinated seeds. Bar $=4 \mathrm{~cm}$

signals were observed in the transgenic leaves compared with the control (Fig. 3A). Similarly, the blue NBT staining signals were significantly more and darker in the CK leaf compared with that in ST7-OE1 and ST7-OE2 lines (Fig. 3B). These results demonstrated that the transgenic cotton plants had a better ability to scavenge $\mathrm{H}_{2} \mathrm{O}_{2}$ and superoxide radicals compared with the $\mathrm{CK}$ plants.

\section{ThST7 improved cotton yield in field}

To detect the effect of ThST7 on cotton yield, we performed a field trial in saline soil as described in "Methods" section. Under normal condition, there was no significant difference in cotton yield per plot between the $\mathrm{CK}$ and transgenic lines, while under $0.4 \% \mathrm{NaCl}$ stress, cotton yield of CK was lower than that of ST7-OE1 and ST7-OE2 lines (Fig. 4A). The average boll weight of CK and transgenic lines was almost similar in normal conditions, but under $0.4 \% \mathrm{NaCl}$ stress, boll weight of transgenic lines (ST7-OE1 and ST7-OE2) was heavier than that of CK (Fig. 4B). These results indicated that the overexpression of ThST7 increased cotton yield under salt stress in the field conditions.

The genes involved in ion homeostasis and antioxidation were enriched and upregulated in the transgenic line

To investigate the molecular mechanism by which ThST7 confers salt tolerance in cotton, we compared the transcriptomes between ThST7-OE and CK under both normal and salt stress. Based on the RNA-seq read counts, a total of 9182 differentially expressed genes (DEGs) were observed under the salt-stress treatment versus 1918 DEGs under normal condition. A total of 790 genes were upregulated and 1128 were downregulated under normal conditions, while 4608 were upregulated and 4574 were downregulated under salt stress (Fig. 5A).

Transcriptomic differences between CK and ThST7-OE were determined by performing pairwise comparisons (CK-N vs. ThST7-OE1-N, CK-N vs. CK-S, and CK-S vs. ThST7-OE1-S). Based on these pairwise comparisons we have categorized into three groups: total number of genes found in the CK-N versus ThST7-OE1 are 73 from which 53 overlapped with CK-N versus CK-S. The total number of genes found in CK-N versus CK-S were 7 573, out of which 2707 overlapped with CK-S versus ThST7-OE1-S. The total number of genes found in CK-S versus ThST7-OE1-S were 1 346, and out of which 10 overlapped with CK-N versus ThST7-OE1. Only 5 genes were found overlapped in all of these groups (Fig. 5B).

The DEGs were grouped into several biological processes under normal (Gig. 6A) and salt treatment (Fig. 6B). Abiotic stress-related genes were significantly upregulated in the transgenic plants as compared with the CK under normal and salt stress conditions (Additional file 1: Tables S1 and S2). ThST7-OE plants exhibited a drastic upregulation of genes involved in salt-tolerance such as KEA2, KEA3, NHX2, NHD1, and AKT2 under salt stress conditions as shown by the heat map (Fig. 7). Moreover, the genes encoding antioxidant enzymes such 
A
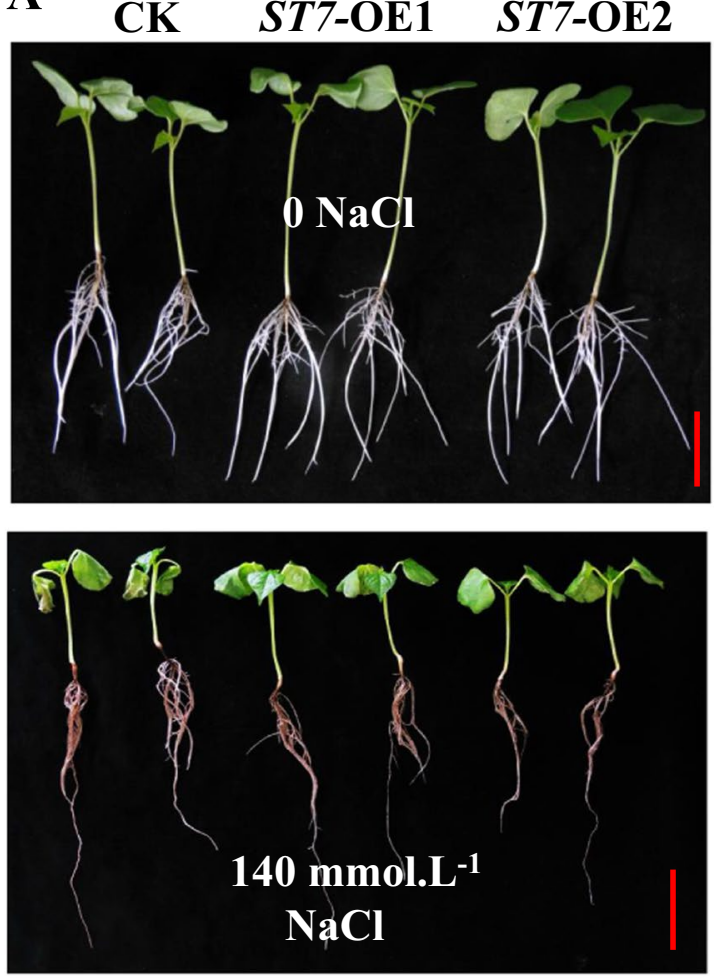

B

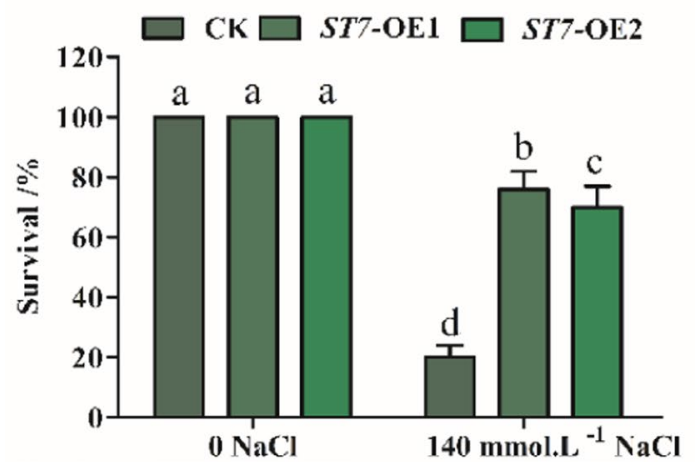

C
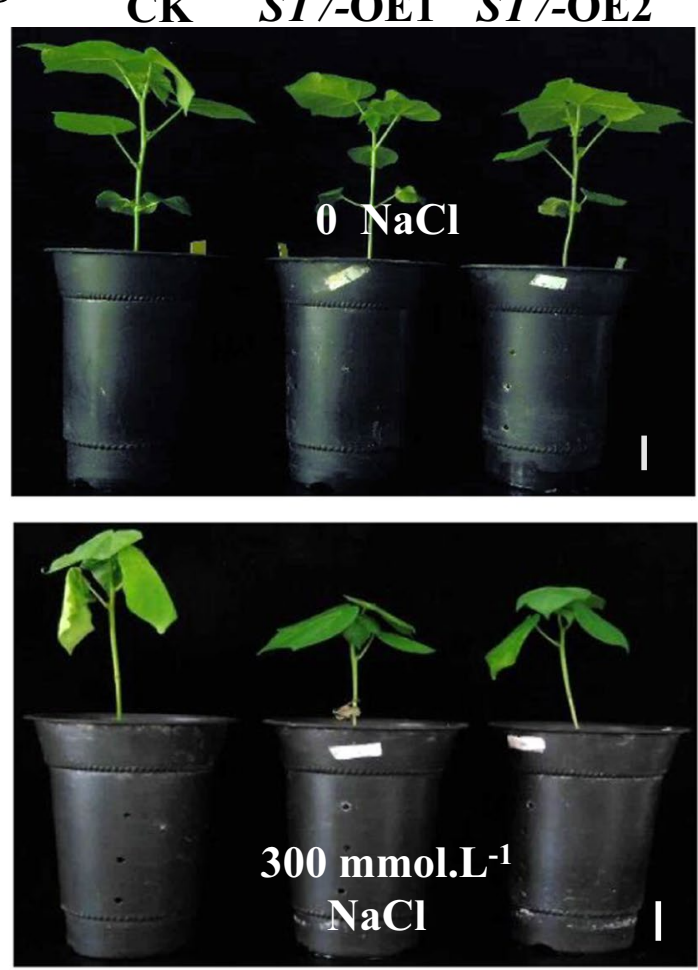

D

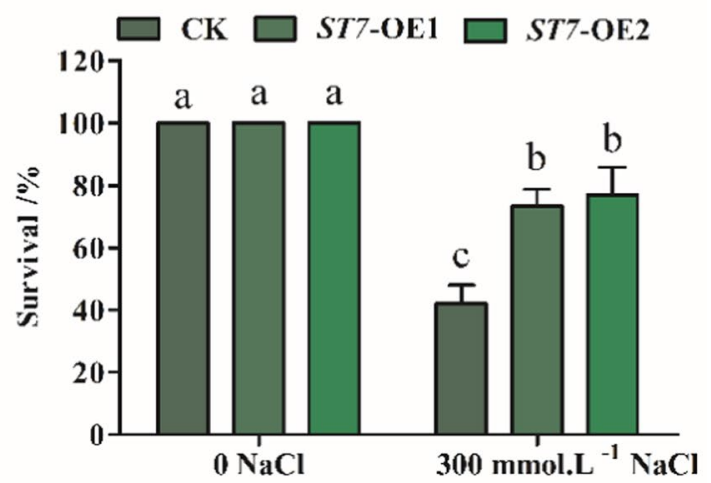

Fig. 2 ThST7 overexpression improved salt tolerance of 2-weeks-old cotton seedlings grown in hydroponic culture or in soil under different salt concentrations. A, B Seeds of the CK and ST7-OE lines germinated in soil for 4 days, transferred to hydroponic culture for 1 week and then treated with $140 \mathrm{mmol} \cdot \mathrm{L}^{-1} \mathrm{NaCl}$ for 3 days. Bar $=4 \mathrm{~cm}$. Values are mean \pm SD (7 plants per replicate, four replicates per treatment). Different letters denote significant differences $(P<0.05)$ from Duncan's multiple range tests. $C$ The 20-days-old seedlings grown in soil were treated with either 0 or $300 \mathrm{mmol} \cdot \mathrm{L}^{-1} \mathrm{NaCl}$ for 10 days before the images were recorded. Bar $=4 \mathrm{~cm}$. D Survival rate of the seedlings as in $\mathbf{C}$. Values are mean $\pm S D(10$ plants per replicate, five replicates per treatment). Different letters denote significant differences $(P<0.05)$ from Duncan's multiple range tests

as ascorbate peroxidase, catalase, peroxidase, and glutathione S-transferase were prominently upregulated in ThST7-OE (Fig. 7, Additional file 1: Table S2). These results demonstrated that ThST7 affected the transcription of an array of salt-responsive genes in cotton.
To find out whether there are homologues of ThST7 in cotton genome, we performed a Blast search using ThST7 protein sequence against cotton genome. The BLAST results showed that there are 23 genes homologous to ThST7 in the Gossypium hirsutum L. genome. Among the 23 genes, 21 genes belong to Stem-specific protein TSJT1 family while the remaining 2 genes are 


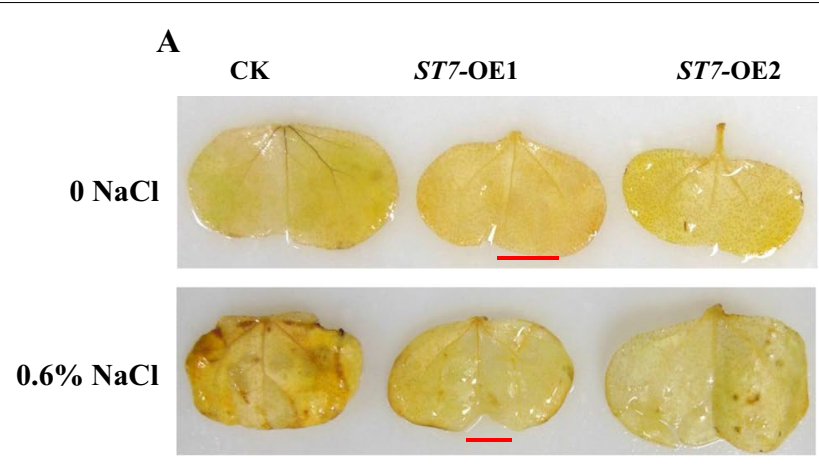

DAB
B
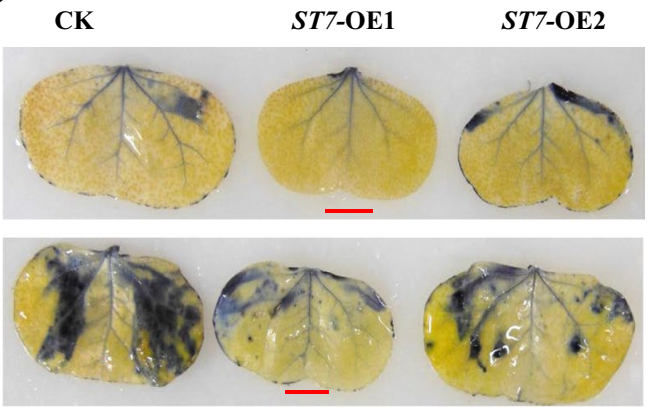

NBT

Fig. 3 DAB and NBT staining. The leaves of control, ST7-OE1, and ST7-OE2 plants treated with either 0 or $140 \mathrm{mmol} \cdot \mathrm{L}^{-1} \mathrm{NaCl}$ for one day before DAB (A) or NBT staining (B). Bar $=1 \mathrm{~cm}$
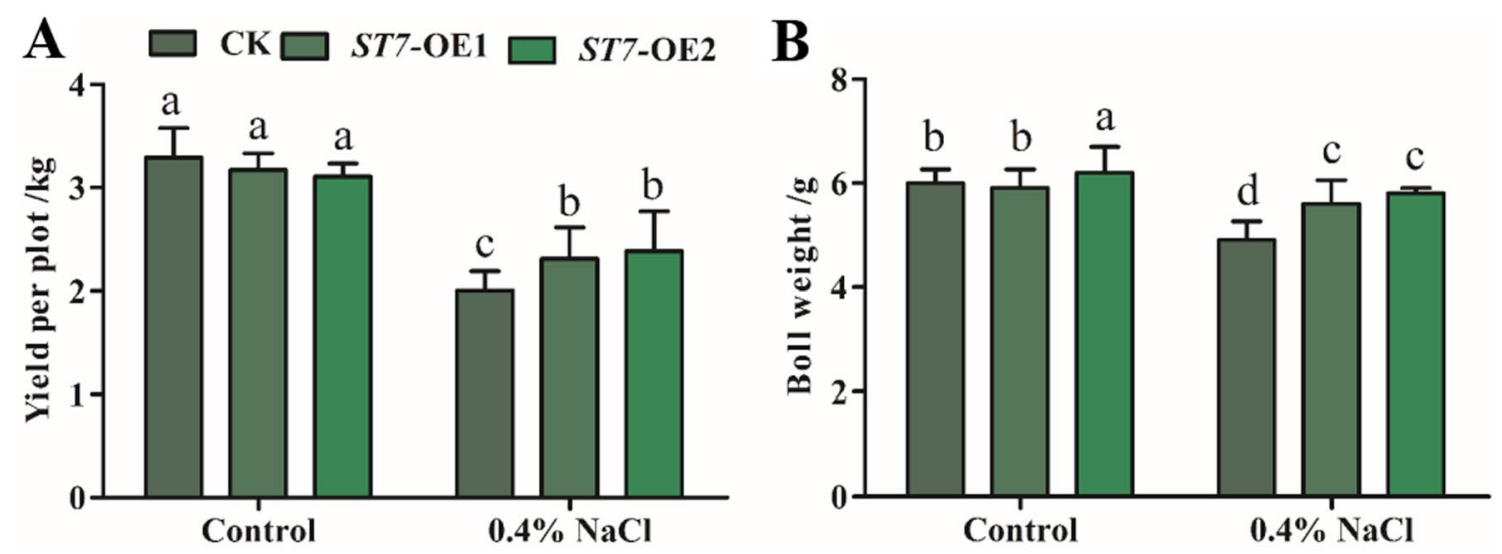

Fig. 4 ThST7 overexpression improved cotton yield in saline field. A Yield per plot of wild type, ST7-OE1 and ST7-OE2 lines in normal soil conditions $(0.1 \% \mathrm{NaCl})$ and saline soil with $0.4 \% \mathrm{NaCl}$. B Average boll weight of the CK and ST7-OE lines as in $\mathbf{A}$
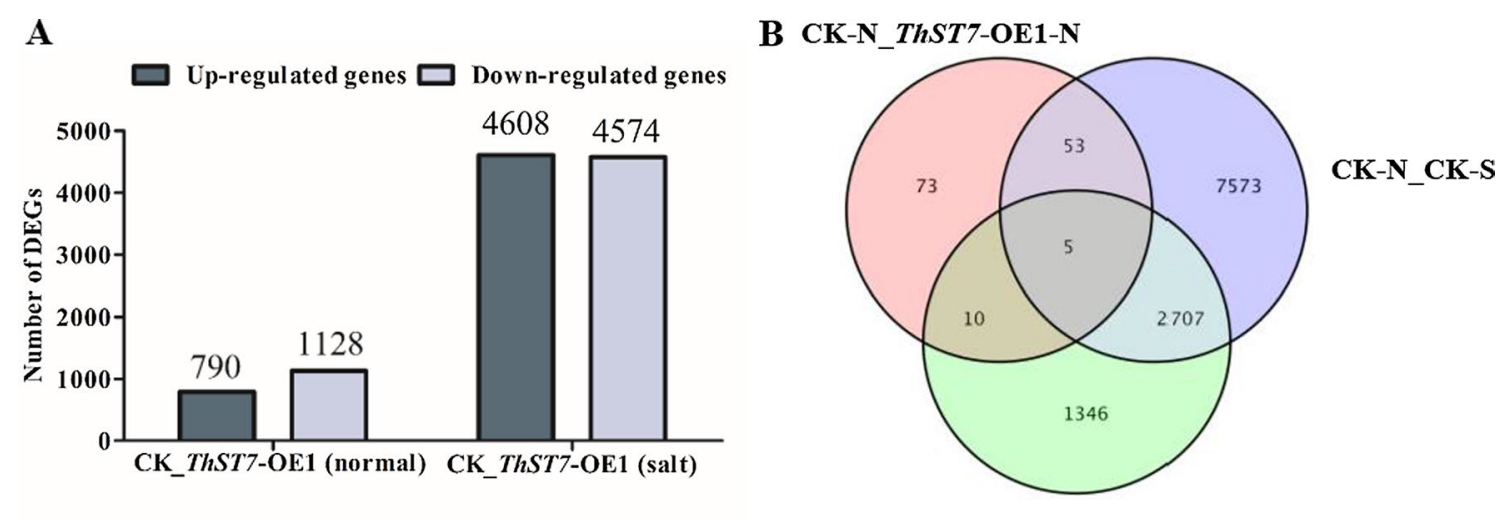

CK-S_ThST7-OE1-S

Fig. 5 RNA-seq of the CK and ST7-OE seedlings under normal and salt stress conditions. A Number of upregulated and downregulated genes in CK and ST7-OE under normal and salt stress condition as revealed by RNA sequencing. B Venn diagrams of the common and specific genes unique and shared between the different pairwise comparisons 


\section{CK_ThST7 under normal condition}

$\mathbf{A}$ Biological_process

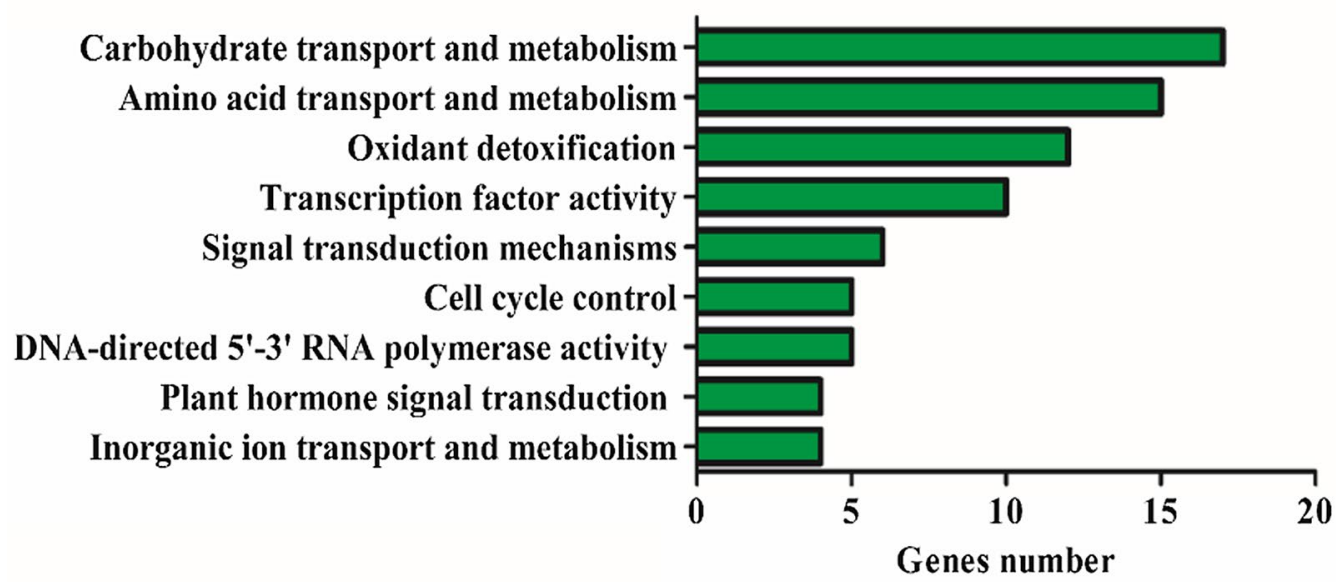

B

CK_ThST7 under salt condition

Biological_process

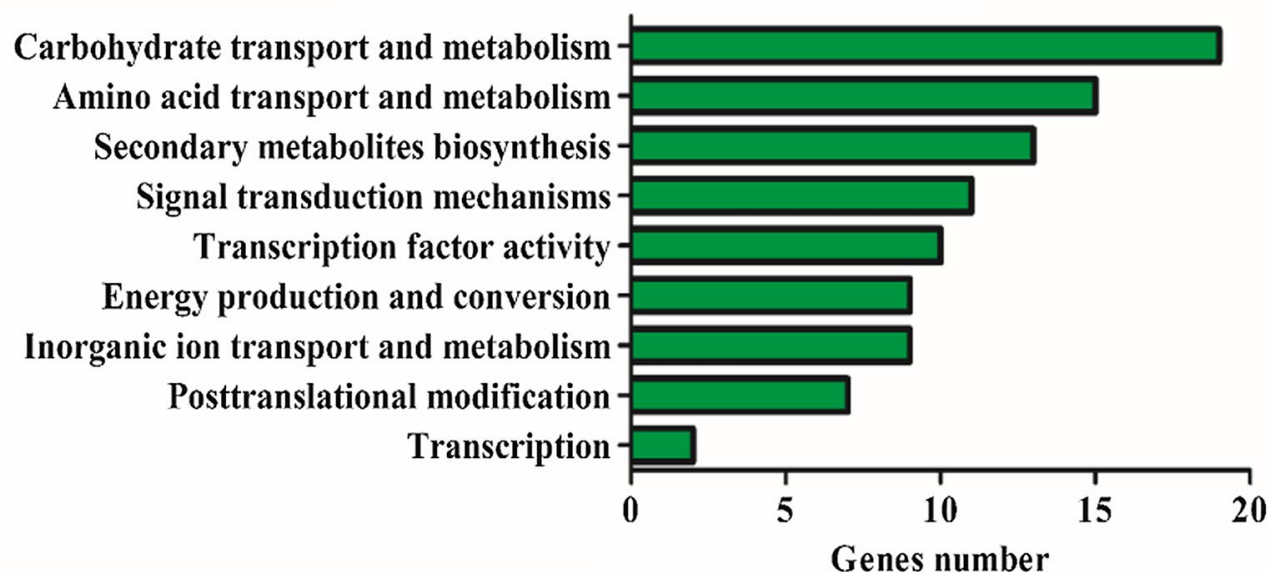

Fig. 6 The Gene ontology $(\mathrm{GO})$ grouped up-regulated genes in different biological processes. A The number of genes involved in the biological processes under normal conditions. B The number of genes involved in the biological processes under salt conditions

annotated as hypothetical protein ERO13 (Additional file 1: Table S3), suggesting that ThST7 proteins might be functionally conserved in cotton.

\section{Discussion}

In this study we evaluated the salt tolerance conferred by ThST7 from Thellungiella halophila and demonstrated the feasibility of this gene improving salt tolerance in cotton.

Cotton is most sensitive to saline stress at germination stage (Peng et al. 2018). A significant reduction in cotton germination was seen in cotton upon exposure to salt stress (Khorsandi and Anagholi 2009; Ma et al.
2011), even a complete inhibition under high salinity stress (Sattar et al. 2010). In our study we observed that the ThST7 transgenic lines displayed early and increased germination under salt stress compared with CK (Fig. 1A, B, C). Thus, ThST7 confers a desirable trait-salt tolerance germination in cotton.

Seedling stage is a significant phase in plant life cycle and vulnerable to environmental stresses including salt stress, which significantly decreases seedling survival (Sattar et al. 2010). Our results showed that upon exposure to salt stress ThST7-OE lines displayed significantly enhanced seedling growth and survival rate as compared with $\mathrm{CK}$ both in soil and hydroponic culture 


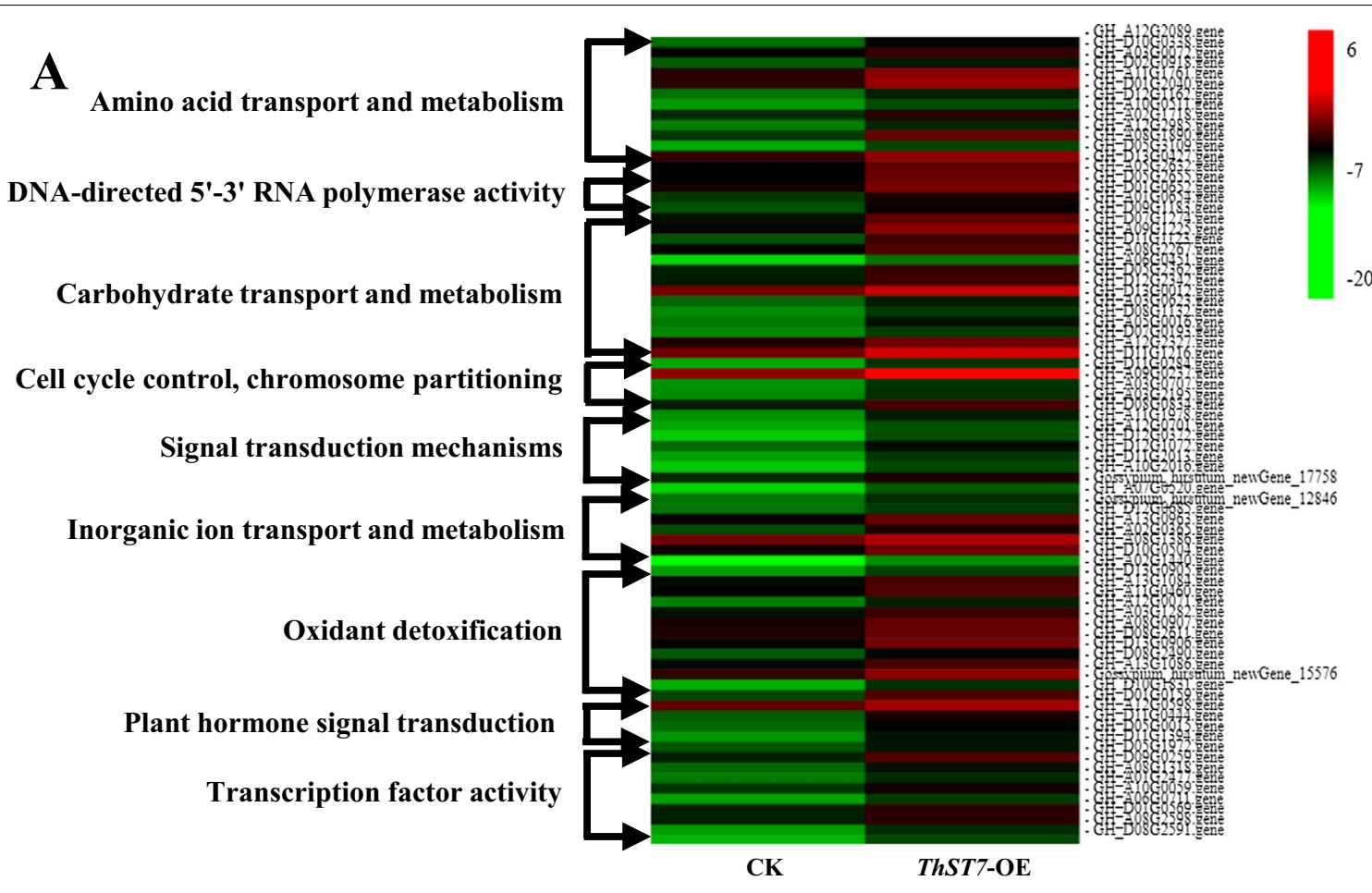

B

Inorganic ion transport and metabolism

Carbohydrate transport and metabolism
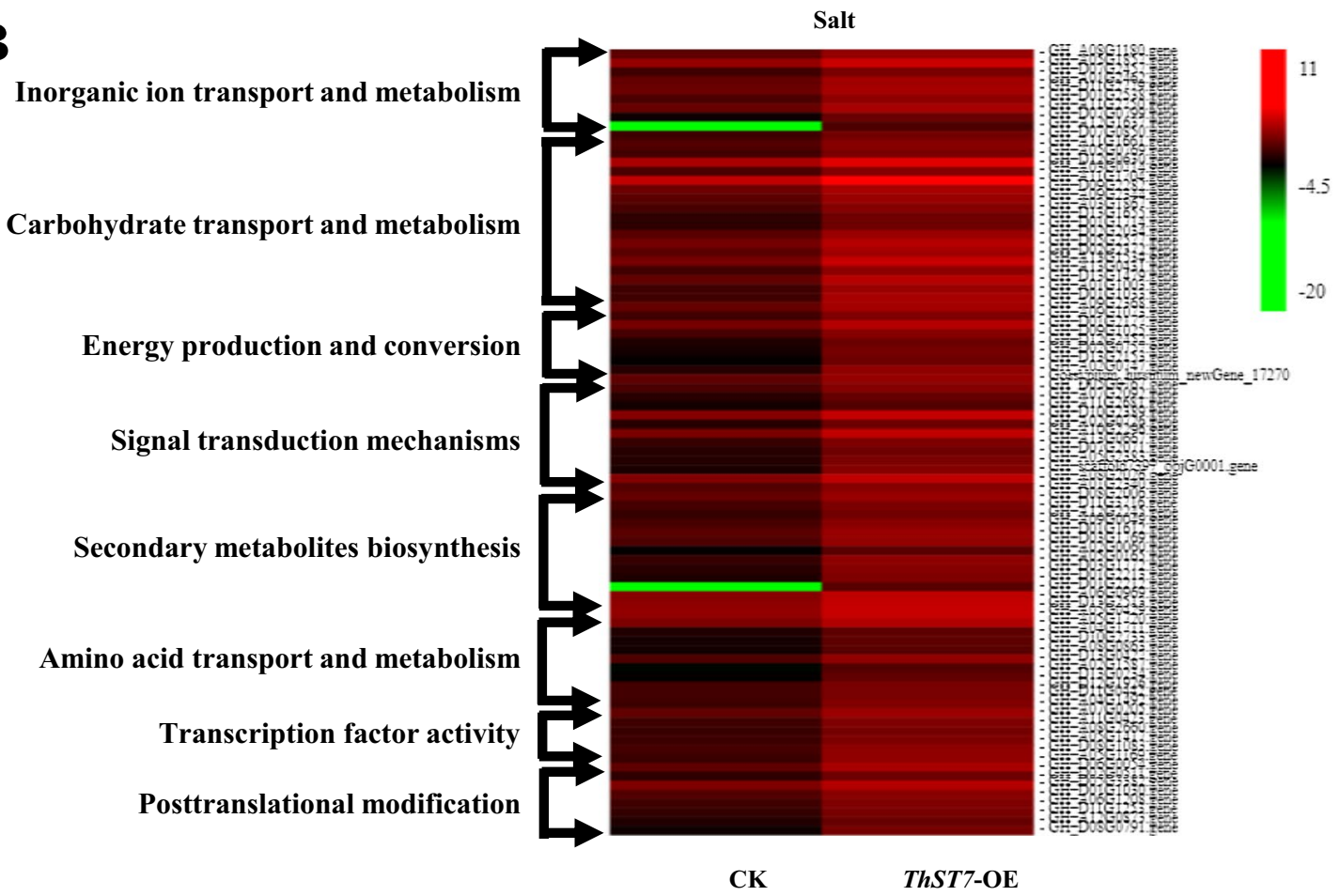

Fig. 7 Heatmap of genes upregulated by in ST7-OE plants under normal conditions. Genes involved in different biological processes in CK and ST7-OE plants under normal conditions $(\mathbf{A})$ and salt stressed conditions $(\mathbf{B})$ were shown. The results were presented as log(2) ratios. Only results with a $P$ value $<0.05$ and that have been confirmed in three independent experiments were included. A color code was used to visualize the data 
(Fig. 2). This demonstrates that ThST7 is capable of enhancing salt tolerance of cotton seedlings, which would greatly benefit cotton seedling establishment in saline soil.

ROS accumulation is induced in plants under salt stress (Choudhury et al. 2017; Luo et al. 2021). An augmented production of ROS (including $\mathrm{OH}^{-}, \mathrm{H}_{2} \mathrm{O}_{2}, \mathrm{O}_{2}$, and $\mathrm{O}_{2}^{-}$) generates cellular oxidative stress that harms membranes and macromolecules in plants (Lin et al. 2020). In our study we observed that ThST7-OE cotton exhibited higher ability of ROS scavenging as evidenced by DAB and NBT staining (Fig. 3). These results signify that ThST7 enhances antioxidant capabilities and protects cotton plants from oxidative damage.

One major goal of crop genetic engineering is to increase crop yield (Bao et al. 2016). High salt content in soil significantly decreases reproductive and vegetative growth of cotton that cause poor fiber quality and low yield (Dong 2012). The yield of cotton decreases with the reduction in boll number and weight (Longenecker 1974). Under saline conditions, decrease in mature bolls takes place due to reduction of fruit bearing position, augmented flower and boll shedding along with delayed flowering (Bernstein and Hayward 1958). Increase in the salt content of soil leads to decrease in the movement of sucrose towards developing bolls thus causing reduction in boll weight (Peng et al. 2016). In our study we demonstrated that in field trails the ThST7-OE lines produced higher yield and average boll weight than CK (Fig. 4) under salinity.

We also carried out RNA transcriptomic analysis of ThST7-OE lines under salt stress. It was revealed that transcript levels of various genes involved in tolerance against salinity stress were upregulated including $N H X 2$, $K E A 2, K E A 3$, NHD1, and AKT2 (Fig. 7, Additional file 1: Table S2). Under salinity stress, plants adapt many strategies to main ion homeostasis via reduction in concentration of $\mathrm{Na}^{+}$and increase in concentration of $\mathrm{K}^{+}$(Cui et al. 2020). The accumulation of $\mathrm{Na}^{+}$in vacuole by sodium/hydrogen exchangers (NHXs) aids in the maintenance of cellular $\mathrm{Na}^{+}$homeostasis (Zhang et al. 2016a, b). The $\mathrm{Na}^{+}$compartmentalization is controlled by $\mathrm{Na}^{+}$/ $\mathrm{H}^{+}$antiporter $(N H X)$ (Apse and Blumwald 2007; Guo et al. 2020). It has been demonstrated that under salinity stress, $N H X$ participates in the $\mathrm{Na}^{+}$partition into vacuoles, which aids the cells to uptake water and sustain the osmotic balance, decreases the noxious effect of salt ions and regulates the cytoplasmic $\mathrm{Na}^{+}$concentration and pH (Apse et al. 1999; Yamaguchi et al. 2001; Guo et al. 2020). In our study we observed that the transcript level of NHX2 is upregulated in transgenic OE lines of cotton compared with that in CK. The function of NHX2 is linked to accumulation of $\mathrm{Na}^{+}$in vacuole and thus leading to salt tolerance in saline environment (Yarra and Kirti 2019).

Along with this, we also observed the transcript levels of $K E A 2$ and $K E A 3$ were upregulated under salt stress in transgenic cotton lines as compared with CK. KEAs are potassium efflux antiporters. KEA2 works as a mediator for monovalent cation/proton exchange and is localized in chloroplast inner envelop membrane (Aranda-Sicilia et al. 2012). However, potassium transporter KEA3 is highly expressed to transport $\mathrm{Na}^{+}$and $\mathrm{Cl}^{-}$into the vacuole for ion absorption and balance adjustments under salt stress (Zhang et al. 2020). It was shown that under osmotic stress $K E A 2$ and $K E A 3$ were involved in hyperosmotic-induced $\mathrm{Ca}^{2+}$ responses. It was demonstrated that KEA2 and KEA3 mutants displayed reduced $\mathrm{Ca}^{2+}$ levels during the hyperosmotic-induced $\mathrm{Ca}^{2+}$ response, thus depicting that KEA2 and KEA3 act as sensors of osmotic stress that are able to regulate the enhancement of $\mathrm{Ca}^{2+}$ (Stephan et al. 2016).

We also observed that the transcript level of $A K T 2$ was also upregulated under salt stress in transgenic cotton lines. AKT2 (Arabidopsis $\mathrm{K}^{+}$transporter) is a $\mathrm{K}^{+}$channel that is permeable to $\mathrm{K}^{+}$but not $\mathrm{Na}^{+}$and is located in leaf phloem tissue (Tian et al. 2021). The maintenance of $\mathrm{Na}^{+} / \mathrm{K}^{+}$homeostasis is important for the survival of plants under salt stress, which is dependent upon the function of $\mathrm{Na}^{+}$and $\mathrm{K}^{+}$transporters (Assaha et al. 2017). The $A K T 2$ knockout rice plants were more sensitive to saline environment compared with the wild types (Tian et al. 2021). In another study it was demonstrated that under salt stress the upregulation of $A K T 2$ led to augmented $\mathrm{K}^{+}$in vascular bundles along with its redistribution between roots and shoots of Arabidopsis (Pilot et al. 2003).

\section{Conclusions}

In conclusion, ThST7 improves cotton seed germination and growth under salt stress. The transgenic cotton lines exhibits increased yield in saline soil in field trial. The salt tolerance phenotype of ThST7-OE plants is supported by the transcriptomic analyses results. Therefore, ThST7 is a candidate gene for salt tolerance improvement in cotton.

\section{Methods}

\section{ThST7 gene cloning and plant transformation}

Full length complimentary ThST7 gene was successfully cloned into a plant binary expression vector (pCB2004) under the control of constitutive promoter CaMV (cauliflower mosaic virus) 35S. ThST7 gene was followed by Nos terminator (Additional file 1: Fig. S1A). NPTII (neomycin phosphotransferase) gene of the vector was used as a selection marker both in the initial screening of transformant bacterial colonies and cotton plants. Transgenic 
cotton lines were obtained by Agrobacterium-mediated transformation ( $\mathrm{Li}$ et al. 2002) of vector construct into callus segment of explant. The regenerated pallets after transformation were transferred to soil to get $\mathrm{T}_{0}$ seeds. $\mathrm{T}_{1}$ seed were harvested by grafting the $\mathrm{T}_{0}$ shots in wild type plants. $\mathrm{T}_{3}$ generation of transformed cotton along with wildtype (CK) was used to carry out this study.

\section{RNA isolation and RT-PCR}

Fresh leaves were taken from plants of both genotypes and ground in mortar and pestle with the use of liquid nitrogen. Total RNA was isolated using Eastep Super Total RNA Extraction Kit (Promega Biotech Co. Ltd., Beijing). Isolated RNA $(1 \mu \mathrm{g})$ from each sample was subjected for reverse transcription reaction. The cDNA was used for RT-PCR analysis to check the expression level of transgenic lines with primers ST7-F (ATGTTGGGAATT TTCAGCGGAG) and ST7-R (TCAATCTGCAAGAAC TGCTGCT). GhHis3 (AF024716) was used as internal control (Forward: TGGGAAGGCTCCAAGGAAGCA, Reverse: CGAGCCAACTGGATGTCCTTG) (Additional file 1: Fig. S1B).

\section{Plant materials}

Cotton (Gossypium hirsutum L.) cultivar R15 was used in this study. Experiments were conducted in the green house facility of School of Life Sciences, University of Science and Technology of China, Hefei, China.

\section{Seed germination}

Transgenic cotton lines along with CK seeds were germinated in long day/night $(16 / 8 \mathrm{~h})$ conditions with temperature $25 \sim 26{ }^{\circ} \mathrm{C}$. For germination under salt tolerance, seeds were germinated under irrigation with 0 or $250 \mathrm{mmol} \cdot \mathrm{L}^{-1}$ of $\mathrm{NaCl}$ for 8 days. Germination rate was observed for each day after sowing.

\section{Survival rates}

Transgenic cotton lines were grown for 4 days in normal growth conditions in soil $\left(16 / 8 \mathrm{~h}\right.$ of light and $\left.28^{\circ} \mathrm{C}\right)$. On the fifth day of germination, seedlings were transferred to hydroponic solution (Hoagland and Arnon 1950) for 1 week and treated with $140 \mathrm{mmol} \cdot \mathrm{L}^{-1} \mathrm{NaCl}$ for another 3 days in the green house under controlled conditions and survival rate was counted. Likewise, transgenic and CK lines were grown in soil for 20 days and treated with 0 or $300 \mathrm{mmol} \cdot \mathrm{L}^{-1} \mathrm{NaCl}$ for another 10 days before survival rate was counted.

\section{DAB and NBT protocol}

To analyze the ROS scavenging capacity of the transgenic lines, DAB and NBT staining were conducted as described (Alvarez et al. 1998). Briefly, the leaves from the ST7-OE1 and ST7-OE2 transgenic lines and CK plants were treated with 0 or $0.6 \% \mathrm{NaCl}$, then stained in the $0.1 \%(\mathrm{w} / \mathrm{v})$ DAB solution in the dark for $18 \mathrm{~h}$. Afterwards, leaves were submerged in $96 \%$ (v/v) ethanol to remove chlorophyll. For NBT staining, the leaves were stained in NBT staining solution for $12 \mathrm{~h}$, then treated with $96 \%(\mathrm{v} / \mathrm{v})$ ethanol to remove chlorophyll.

\section{Field trial of cotton}

To check the performance of ThST7 transgenic cotton, field trials were performed in Experiment Station of Shanxi Agricultural Academy, Yuncheng, Shanxi Province, China from April 2020 to September 2020. Experimental design contained 3 replicate plots per genotype per treatment with plot size of $2.5 \times 6 \mathrm{~m}^{2}$ with random arrangement. During the whole growth period, the control group was grown in the soil with salt $(\mathrm{NaCl})$ content $<0.1 \%$, while the salt stress treatment group was grown in the soil with $0.4 \% \mathrm{NaCl}$. Cotton yield (fiber plus seeds) was recorded at the end of the field trial.

\section{RNA sequencing}

The plants were grown hydroponically with the conditions described above as $\mathrm{CK}$ and salt treated lines (140 $\left.\mathrm{mmol} \cdot \mathrm{L}^{-1} \mathrm{NaCl}\right)$. The 16 -days-old seedlings were sampled for RNA sequencing. A total of 20 seedlings of the salt treated, and controls were collected. RNA library construction and sequence analysis were conducted as described (Hu et al. 2016).

\section{Accession numbers}

Sequence data from this article can be found in the National Center for Biotechnology Information (www. ncbi.nlm.nih.gov/) or Arabidopsis TAIR database (https:// www.arabidopsis.org/) under the following accession numbers: AtNHX7: NM_126259, ThST7-5-2: EU714069, EU714068, ST225: EU714080, GhHIS3: LOC107951735, AT5G19140: AK318630, AtNHX1: AT5G27150.

\section{Supplementary Information}

The online version contains supplementary material available at https://doi. org/10.1186/s42397-021-00108-1.

Additional file 1: Fig. S1. Overexpression construct of ThST7 and verification of the transgenic lines. Table $\mathbf{S 1}$. Abiotic stress-related genes that are significantly upregulated in the transgenic line compared to wild type control under normal condition. Table S2. Abiotic stress-related genes that are significantly upregulated in the transgenic line compared to wild type control under salt stress condition. Table S3. ThST7 homologues in cotton genome.

\section{Acknowledgements}

This work was supported by grants from Ministry of Science and Technology of China (Grant No. 2016ZX08005004-003). 


\section{Authors' contributions}

Alfatih A, Xiang CB and Wu SJ designed the experiments. Ali M, Nazish T, Javaid A, Wu J performed most of the experiments and data analyses. Zhu YH, Li J, Zhang HY, and Wu SJ conducted field trials and data analyses. Ali M and Alfatih A wrote the manuscript. Alfatih A, Wu SJ and Xiang CB revised the manuscript and supervised the project. All authors read and approved the final manuscript.

\section{Funding}

Ministry of Science and Technology of China (Grant No. 2016ZX08005004-003).

\section{Availability of data and materials}

All data generated or analyzed during this study are included in this published article [and its supplementary information files]

\section{Declarations}

\section{Ethics approval and consent to participate}

Not applicable.

\section{Consent for publication}

The manuscript has not been published or submitted for

publication elsewhere.

\section{Competing interests}

The authors declare no competing interests.

\section{Author details}

'Division of Molecular \& Cell Biophysics, School of Life Sciences, Hefei National Science Center for Physical Sciences at the Microscale, University of Science and Technology of China, The Innovative Academy of Seed Design, Chinese Academy of Sciences, Hefei, Anhui, China. ${ }^{2}$ Institute of Cotton Research, Shanxi Agricultural University, Yuncheng 044000, China. ${ }^{3}$ College of Life Sciences, Shanxi Agricultural University, Taiyuan 030031, China.

Received: 2 September 2021 Accepted: 2 December 2021

Published online: 04 January 2022

\section{References}

Agarwal G, Rajavel M, Gopal B, et al. Structure-based phylogeny as a diagnostic for functional characterization of proteins with a cupin fold. PLOS ONE 2009;4(5):e5736. https://doi.org/10.1371/journal.pone.0005736.

Alvarez ME, Pennell RI, Meijer P-J, et al. Reactive oxygen intermediates mediate a systemic signal network in the establishment of plant immunity. Cell. 1998;92(6):773-84. https://doi.org/10.1016/S0092-8674(00)81405-1.

Apse MP, Blumwald E. $\mathrm{Na}^{+}$transport in plants. FEBS Lett. 2007;581(12):224754. https://doi.org/10.1016/j.febslet.2007.04.014.

Apse MP, Aharon GS, Snedden WA, et al. Salt tolerance conferred by overexpression of a vacuolar $\mathrm{Na}^{+} / \mathrm{H}^{+}$antiport in Arabidopsis. Science. 1999;285(5431):1256-8. https://doi.org/10.1126/science.285.5431.1256.

Aranda-Sicilia MN, Cagnac O, Chanroj S, et al. Arabidopsis KEA2, a homolog of bacterial KefC, encodes a $\mathrm{K}^{+} / \mathrm{H}^{+}$antiporter with a chloroplast transit peptide. Biochim Biophys Acta (BBA) Biomembr. 2012;1818(9):2362-71. https://doi.org/10.1016/j.bbamem.2012.04.011

Assaha DV, Ueda A, Saneoka $\mathrm{H}$, et al. The role of $\mathrm{Na}^{+}$and $\mathrm{K}^{+}$transporters in salt stress adaptation in glycophytes. Front Physiol. 2017;8:509. https://doi. org/10.3389/fphys.2017.00509.

Bao AK, Du BQ, Touil L, et al. Co-expression of tonoplast Cation/ $/ \mathrm{H}^{+}$antiporter and $\mathrm{H}^{+}$-pyrophosphatase from xerophyte Zygophyllum xanthoxylum improves alfalfa plant growth under salinity, drought and field conditions. Plant Biotechnol J. 2016;14(3):964-75. https://doi.org/10.1111/pbi.12451.

Bernstein L, Hayward H. Physiology of salt tolerance. Annu Rev Plant Physiol. 1958;9(1):25-46. https://doi.org/10.1146/annurev.pp.09.060158.000325.

Blumwald E. Sodium transport and salt tolerance in plants. Curr Opin Cell Biol. 2000;12(4):431-4. https://doi.org/10.1016/S0955-0674(00)00112-5.

Cheng C, Zhang Y, Chen X, et al. Co-expression of AtNHX1 and TsVP improves the salt tolerance of transgenic cotton and increases seed cotton yield in a saline field. Mol Breed. 2018;38(2):19. https://doi.org/10.1007/ s11032-018-0774-5.

Choudhury FK, Rivero RM, Blumwald E, et al. Reactive oxygen species, abiotic stress and stress combination. Plant J. 2017;90(5):856-67. https://doi.org/ 10.1111/tpj.13299.

Cui J, Hua Y, Zhou T, et al. Global landscapes of the $\mathrm{Na}^{+} / \mathrm{H}^{+}$antiporter (NHX) family members uncover their potential roles in regulating the rapeseed resistance to salt stress. Int J Mol Sci. 2020;21(10):3429. https://doi.org/10. 3390/ijms21103429.

Darko E, Khalil R, Dobi Z, et al. Addition of Aegilops biuncialis chromosomes $2 \mathrm{M}$ or $3 \mathrm{M}$ improves the salt tolerance of wheat in different way. Sci Rep. 2020;10(1):1-13. https://doi.org/10.1038/s41598-020-79372-1.

Dong $\mathrm{H}$. Combating salinity stress effects on cotton with agronomic practices. Afr J Agric Res. 2012;7(34):4708-15. https://doi.org/10.5897/AJAR12.501.

Du J, Huang YP, Xi J, et al. Functional gene-mining for salt-tolerance genes with the power of Arabidopsis. Plant J. 2008;56(4):653-64. https://doi.org/10. 1111/j.1365-313X.2008.03602.x

Flowers TJ, Colmer TD. Salinity tolerance in halophytes. New Phytol. 2008;179(4):945-63. https://doi.org/10.1111/j.1469-8137.2008.02531.x.

Guo Q, Tian XX, Mao PC, Meng L. Overexpression of Iris lactea tonoplast Na+/ $\mathrm{H}^{+}$antiporter gene I/NHX confers improved salt tolerance in tobacco. Biol Plant. 2020;64:50-7. https://doi.org/10.32615/bp.2019.126.

Hoagland DR, Arnon DI. The water-culture method for growing plants without soil. Circular. California Agricultural Experiment Station, 2nd ed. 1950. p. 347. https://www.cabdirect.org/cabdirect/abstract/19500302257.

Hu Y, Xue YQ, Liu JS, et al. Hybrid lethality caused by two complementary dominant genes in cabbage (Brassica oleracea L.). Mol Breed. 2016;36(6):1-10. https://doi.org/10.1007/s11032-016-0498-3.

Khorsandi F, Anagholi A. Reproductive compensation of cotton after salt stress relief at different growth stages. J Agron Crop Sci. 2009;195(4):278-83. https://doi.org/10.1111/j.1439-037X.2009.00370.x.

Li XB, Cai L, Cheng NH, et al. Molecular characterization of the cotton GhTUB1 gene that is preferentially expressed in fiber. Plant Physiol. 2002;130(2):666-74. https://doi.org/10.1104/pp.005538.

Lin IS, Wu YS, Chen CT, et al. AtRBOH I confers submergence tolerance and is involved in auxin-mediated signaling pathways under hypoxic stress. Plant Growth Regul. 2017;83(2):277-85. https://doi.org/10.1007/ s10725-017-0292-1.

Lin YJ, Yu XZ, Li YH, et al. Inhibition of the mitochondrial respiratory components (Complex I and Complex III) as stimuli to induce oxidative damage in Oryza sativa L. under thiocyanate exposure. Chemosphere. 2020:243:125472. https://doi.org/10.1016/j.chemosphere.2019.125472.

Longenecker D. The influence of high sodium in soils upon fruiting and shedding, boll characteristics, fiber properties, and yields of two cotton species. Soil Sci. 1974;118(6):387-96.

Luo X, Dai Y, Zheng C, et al. The ABI4-RbohDNTC2 regulatory module promotes reactive oxygen species (ROS) accumulation to decrease seed germination under salinity stress. New Phytol. 2021;229(2):950-62. https://doi.org/10.1111/nph.16921.

Lv S, Zhang K, Gao Q, et al. Overexpression of an $\mathrm{H}^{+}$-PPase gene from Thellungiella halophila in cotton enhances salt tolerance and improves growth and photosynthetic performance. Plant Cell Physiol. 2008:49(8):1150-64. https://doi.org/10.1093/pcp/pcn090.

Ma X, Dong H, Li W. Genetic improvement of cotton tolerance to salinity stress. Afr J Agric Res. 2011;6(33):6797-803.

Ma W, Ren Z, Zhou Y, et al. Genome-wide identification of the Gossypium hirsutum NHX genes reveals that the endosomal-type GhNHX4A is critical for the salt tolerance of cotton. Int J Mol Sci. 2020;21(20):7712. https://doi. org/10.3390/ijms21207712

Martinez G, Abdelraheem A, Darapuneni M, et al. Evaluation of a multi-parent advanced generation inter-cross (MAGIC) introgressed line population for Verticillium wilt resistance in Upland cotton. Euphytica. 2018;214(10):197. https://doi.org/10.1007/s10681-018-2278-0.

Martinoia E, Maeshima M, Neuhaus HE. Vacuolar transporters and their essential role in plant metabolism. J Exp Bot. 2007;58(1):83-102. https://doi. org/10.1093/jxb/erl183.

Munns R, Tester M. Mechanisms of salinity tolerance. Annu Rev Plant Biol. 2008;59:651-81. https://doi.org/10.1146/annurev.arplant.59.032607. 092911. 
Pál M, Majláth I, Németh E, et al. The effects of putrescine are partly overlapping with osmotic stress processes in wheat. Plant Sci. 2018;268(3):67-76. https://doi.org/10.1016/j.plantsci.2017.12.011.

Parida AK, Das A, Mittra B. Effects of salt on growth, ion accumulation, photosynthesis and leaf anatomy of the mangrove, Bruguiera parviflora. Trees. 2004;18(2):167-74. https://doi.org/10.1007/s00468-003-0293-8.

Pasapula V, Shen G, Kuppu S, et al. Expression of an Arabidopsis vacuolar $\mathrm{H}^{+}$-pyrophosphatase gene (AVP1) in cotton improves drought- and salt tolerance and increases fibre yield in the field conditions. Plant Biotechnol J. 2011;9(1):88-99. https://doi.org/10.1111/j.1467-7652.2010.00535.x.

Peng J, Liu J, Zhang L, et al. Effects of soil salinity on sucrose metabolism in cotton leaves. PLoS ONE. 2016;11(5):e0156241. https://doi.org/10.1371/ journal.pone. 0156241

Peng Z, He S, Gong W, et al. Integration of proteomic and transcriptomic profiles reveals multiple levels of genetic regulation of salt tolerance in cotton. BMC Plant Biol. 2018;18(1):1-19. https://doi.org/10.1186/ s12870-018-1350-1.

Pilot G, Gaymard F, Mouline K, et al. Regulated expression of Arabidopsis Shaker $\mathrm{K}^{+}$channel genes involved in $\mathrm{K}^{+}$uptake and distribution in the plant. Plant Mol Biol. 2003;51(5):773-87. https://doi.org/10.1023/A:10225 97102282.

Sattar S, Hussnain T, Javaid A. Effect of $\mathrm{NaCl}$ salinity on cotton (Gossypium arboreum L.) grown on MS medium and in hydroponic cultures. J Anim Plant Sci. 2010;20:87-9.

Stephan AB, Kunz HH, Yang E, et al. Rapid hyperosmotic-induced $\mathrm{Ca}^{+}$ responses in Arabidopsis thaliana exhibit sensory potentiation and involvement of plastidial KEA transporters. Proc Natl Acad Sci. 2016;113(35):E5242-9. https://doi.org/10.1073/pnas.1519555113.

Tester M, Davenport R. $\mathrm{Na}^{+}$tolerance and $\mathrm{Na}^{+}$transport in higher plants. Ann Bot. 2003;91(5):503-27. https://doi.org/10.1093/aob/mcg058.

Tian Q, Shen L, Luan J, et al. Rice Shaker potassium channel OsAKT2 positively regulates salt tolerance and grain yield by mediating $\mathrm{K}^{+}$redistribution. Plant Cell Environ. 2021;44:2951-65. https://doi.org/10.1111/pce.14101.

Wang W, Vinocur B, Altman A. Plant responses to drought, salinity and extreme temperatures: towards genetic engineering for stress tolerance. Planta. 2003;218(1):1-14. https://doi.org/10.1007/s00425-003-1105-5.

Yamaguchi T, Fukada-Tanaka S, Inagaki Y, et al. Genes encoding the vacuolar $\mathrm{Na}^{+} / \mathrm{H}^{+}$exchanger and flower coloration. Plant Cell Physiol. 2001;42(5):451-61. https://doi.org/10.1093/pcp/pce080.

Yarra R, Kirti P. Expressing class I wheat NHX (TaNHX2) gene in eggplant (Solanum melongena $\mathrm{L}$.) improves plant performance under saline condition. Funct Integr Genomics. 2019;19(4):541-54. https://doi.org/10.1007/ s10142-019-00656-5.

Zhang F, Zhu G, Du L, et al. Genetic regulation of salt stress tolerance revealed by RNA-Seq in cotton diploid wild species, Gossypium davidsonii. Sci Rep. 2016a;6(1):1-15. https://doi.org/10.1038/srep20582.

Zhang K, Song J, Chen X, et al. Expression of the Thellungiella halophila vacuolar $\mathrm{H}^{+}$-pyrophosphatase gene (TSVP) in cotton improves salinity tolerance and increases seed cotton yield in a saline field. Euphytica. 2016b;211(2):231-44. https://doi.org/10.1007/s10681-016-1733-z.

Zhang X, Yao Y, Li X, et al. Transcriptomic analysis identifies novel genes and pathways for salt stress responses in Suaeda salsa leaves. Sci Rep. 2020;10(1):1-12.

Zhu JK. Salt and drought stress signal transduction in plants. Annu Rev Plant Biol. 2002;53(1):247-73. https://doi.org/10.1146/annurev.arplant.53. 091401.143329

Ready to submit your research? Choose BMC and benefit from:

- fast, convenient online submission

- thorough peer review by experienced researchers in your field

- rapid publication on acceptance

- support for research data, including large and complex data types

- gold Open Access which fosters wider collaboration and increased citations

- maximum visibility for your research: over $100 \mathrm{M}$ website views per year

At BMC, research is always in progress.

Learn more biomedcentral.com/submissions 